\title{
Clinical and metabolic response to soy administration in older women with metabolic syndrome: a randomized controlled trial
}

\author{
Afsaneh Bakhtiari ${ }^{1,5}$, Karimollah Hajian-Tilaki ${ }^{2}$, Shabnam Omidvar ${ }^{3,5}$ and Fatemeh Nasiri-Amiri ${ }^{4,5^{*}}$ (1)
}

\begin{abstract}
Background: There are many studies on the health effects of soy, only a few describe the effects of the simultaneous use of two types of soy on multiple components of metabolic syndrome (MetS). The present study was designed to determine the effects of roasted soy-nut and textured soy protein (TSP) intake on clinical and metabolic status of older women with MetS borderline parameters.

Method: This randomized, single-blind, controlled clinical trial included 75 women $\geq 60$ years old with a diagnosis of MetS based on ATP III criteria. The participants were randomly allocated into three groups of 25 people; soy-nut, TSP and control groups for 12 week. Fasting blood samples were taken at the beginning and end of the trial to compare the metabolic responses. All participants provided three dietary records and physical activity records during the intervention. We used the Kolmogorov-Smirnov, ANOVA, ANCOVA, paired-t test, and the Generalized Linear Model (GLM) repeated measures analysis.
\end{abstract}

Results: Dietary intake and physical activity of the participants in two groups were not significantly different. After 12 weeks of intervention the participants who received soy-nut had a significant decrease in total cholesterol (TC) $(p<0.001)$, low density lipoprotein, very low density lipoprotein, apolipoprotein B100, fasting blood glucose, insulin $(p<0.05)$, HOMA-IR, malondialdehyde (MDA) $(p<0.01)$ level. Morever, a significant increase in total antioxidant capacity $(T A C)(p<0.01)$ level compared with the control group. At the same time, the TSP brought significant decrease only in TC, insulin, MDA $(p<0.05)$ level and a significant increase in total TAC $(p<0.05)$ level. We did not find any significant effect in intervention groups, on apolipoprotein Al, triglyceride (TG), high density lipoprotein (HDL-C), TG/HDL, C-reactive protein and fibrinogen levels after intervention.

Conclusion: Short-term intakes of roasted soy-nut and TSP have shown to improve the lipid profiles, markers of glucose intolerance and oxidative stress; although the roasted soy-nut was more effective than TSP. Therefore, a moderate daily intake of roasted soy-nut as snacks or TSP as a meal complement by individuals with borderline parameters of MetS can be a safe and a practical modality to avoid the progression of the disease as well as to limit the side effects of drug intake.

Trial registration MUBABOL.REC.1388.1

Keywords: Metabolic syndrome, Elderly women, Soy protein, Soy-nut

\footnotetext{
*Correspondence: nasiri_fa@yahoo.com

${ }^{4}$ Infertility and Health Reproductive Research Center, Health Research

Institute, Babol University of Medical Sciences, Babol, Iran

Full list of author information is available at the end of the article
} 


\section{Introduction}

Metabolic syndrome (MetS), and its various features involving all body organs in the pathological process, is a major public health problem that causes the global burden of disease. The main concern of MetS is that each of its individual components is associated with increased cardiovascular disease (CVD) risks, while the presence of MetS greatly augments CVD morbidity and mortality [1]. Mets is caused by increase of visceral fats which promotes synthesis of proinflammatory cytokines, which in turn results in the development of reactive oxygen species (ROS), thrombotic and atherogenic factors, which are all conditions with Mets [2]. Meanwhile, existing data suggest that the incidence of MetS is rising at an alarming rate in the world [3] and Iran [4]. The prevalence of MetS has been reported to be higher in Iran in compare to other Asian and European countries [1, 3, 4]. The prevalence of the MetS increases with age, and reaches the peak in the fifth decade of life. According to the definition of ATPIII, more than half of the population aged 60 years and higher, have MetS in Iran; prevalence in elderly women is higher than men [4].

Menopausal status and aging are linked to some components of MetS. With increase in age, decrease in muscle mass occurs, which this leads to decreased peripheral glucose uptake and increased oxidative stress. This also causes exacerbation of impaired insulin secretion and progression of atherosclerosis and ultimately hypertension [5]. Thus, treatment of MetS can prevent from disability and will promote healthy aging.

However, treatment of MetS must address the multipathological process of MetS, with each component identified and aggressively targeted for treatment. In theory, it is possible to treat each of the symptoms of MetS using the present optimal method or pharmacological agent, as this will result in treating obesity, hypertension, dyslipidaemia, hyperglycaemia, and exaggerated platelet aggregation, each with a different mode. This may lead to separate treatments for numerous disorders [2]. Nevertheless, the focus of today's efforts is to discover and apply methods that simultaneously mitigate several morbid features of MetS, by treating the underlying link or cause rather than by treating each discrete manifestation [6]. There is evidence which indicate that modifications of dietary habits and lifestyle patterns are the first-line therapy to prevent and treat MetS. It is known that soy can have an important role in preventing vascular diseases through its effects on insulin resistance, inflammatory process affecting vascular disease, and oxidative stress. Soy consumption has been reported to beneficially affect features of MetS in animal models [7-10], and also in humans to some extent $[11,12]$. Several studies have consistently reported the effects of soy on cardiovascular risks such as, lipid profile [13, 14], glycemia status $[15,16]$, proinflammatory $[17,18]$, prothrombotic $[19$, 20] and oxidative stress markers [21, 22]; however, not all studies agree on these effects [23-27].

Soybeans are the most excellent source of unsaturated fatty acids, dietary fiber, isoflavones, and antioxidants. Soybeans are also fiber-rich, nutrient-dense, and are high-quality sources of protein; all requirements of a dietary intervention to reduce cardiometabolic risk. The content and bioavailability of protein, fats, minerals and isoflavones in dry beans and soy foods vary according to their processing methods and phytate content.

Soy nuts are made by soaking dry soybeans and baking them in one layer on a well-oiled cookie sheet at around $350{ }^{\circ} \mathrm{F}\left(190{ }^{\circ} \mathrm{C}\right)$ during 30 to $50 \mathrm{~min}$ until well browned. Soy proteins are also divided into different classes according to their production methods. Textured Soy Protein (TSP) is manufactured by forming doughs from high nitrogen solubility index, dehulled and defatted soy flour with water in a screw-type extruder and heated with steam. Therefore TSP is high in protein and low in fat [28]. Texturization of the flour, leads to a decrease of the isoflavone content in the TSP. Dehulling was also shown to be a way of decreasing the isoflavone content of the flour prepared from raw seeds. Heat treatment of soy increases the digestibility of the protein and enhances the nutritional quality of soybeans. The soy cotyledon storage proteins can be extracted most efficiently from dehulled and defatted soybeans that have undergone only a minimal heat treatment so that the protein is close to being native or undenatured. All of these processes result in a product that is $70 \%$ protein, $20 \%$ carbohydrates $(2.7$ to $5 \%$ crude fiber), $6 \%$ ash and about $1 \%$ oil; but the solubility may differ [29].

Considering the health effects of soybeans, as well as the impact of the production process on some of the soybean's active ingredients, the question arises as to how the health effects of soy-processed products compare to other products. For instance, roasted soy-nuts are made from whole soy beans which are non-processed products. In contrast, TSP comes in the form of flakes, like of ground meat that comes from manufacturing process. Therefore, this study was specifically designed to determine the effects of roasted soy-nuts in the natural state of soybean against TSP, as a processed soy product on the full profile of MetS in women aged 60 years and higher. The results of this study can be taken as a practical way to reduce the need for medical treatment in elderly women with MetS through simultaneous improvement of multiple metabolic disorders. 


\section{Method and material Participants}

Seventy-five peoples with MetS whose age ranged between 60 and 70 years were recruited for this randomized, single-blind, parallel controlled trial. To determine the sample size, we applied a randomized clinical trial sample size formula considering type I $(\alpha)$ and type II errors ( $\beta$ ) of 0.05 and 0.20 (power $80 \%$ ), respectively; in order to detect the effect size of 0.8 in metabolic response between comparison groups. Thus allocated sample size was 21 subjects for each group and by considering a \%15 dropout rate, 75 participants were included in the study.

\section{Recruitment and screening}

The volunteers were recruited by advertisements in the Rural Health Centers affiliated with the Babol University of Medical Sciences (BUMS), Iran. Thus, one cohort of 306 volunteers was initially screened via personal basic interview using a prescreening evaluation, including their medical history, medication, lipid and glucose records, abdominal obesity and hypertension. A total of 142 volunteers were excluded and 164 subjects who meet the initial criteria was be invited to determine their eligibility by assessment of central obesity, blood pressure, fasting blood glocuse (FBG), triglyceride (TG) and high density lipoprotein (HDL-C). Among them, 75 eligible subjects with a diagnosis of MetS based on ATPIII criteria [4], and without receiving any medications for the treatment of diabetes, hypertension, and hyperlipidemia were included in the study. However individuals who received medication because of the following lab results LDL-C above 160 or $189 \mathrm{mg} / \mathrm{dl}$ depending on the number of CVD risk factors, TG' $500 \mathrm{mg} / \mathrm{dl}, \mathrm{FBG} \geq 126 \mathrm{mg} /$ $\mathrm{dl}$, and blood pressure $\geq 140 / 90 \mathrm{~mm} \mathrm{Hg}$ didn't enter the study [30-32].

Exclusion criteria were a history of kidney, liver, thyroid, infectious diseases, cancer, and CVD, and taking antibiotic, dietary supplements or probiotic supplements during the previous 3 mo. All procedures were carried out on the basis of ethics standards of the responsible committee on human experimentation (institutional and national) and to the Declaration of Helsinki. In addition, the ethics committee of BUMS approved the study (NO.:MUBABOL.REC.1388.1). All participants provided an informed written and signed consent form. All patients provided written informed consent.

\section{Study design}

In the present study, the participants were randomly allocated into three groups to receive soy-nut $(n=25)$ or TSP $(n=25)$ or control group $(n=25)$ using a table of random numbers generated by Microsoft Excel.
Randomization and allocation was concealed from those who did blood biochemical and statistical analysis. Soy used in this study, comprised of roasted soynut and TSP, both provided by the Max Soy Company in Tehran, Iran. The participants were provided with 2 weekly supply of soy in 490 gr bags. A daily dosage of $35 \mathrm{~g}$ of roasted soy-nut or TSP was consumed by the intervention groups during the 12-week intervention. The control group received no intervention, since the participants in the intervention groups were consuming natural soy products not pills, so it was impossible to apply any placebo for the control group.

The amount of soy used in this study was selected based on previous studies have shown that soy isoflavones amounts equal to or greater than $90 \mathrm{mg}$ per day can reduce insulin levels in healthy postmenopausal women [33, 34]. This is consistent with the amount of isoflavone used in this study $(96.2 \mathrm{mg}$ in TSP and $117.2 \mathrm{mg}$ in roasted soy-nut groups). The nutrient composition of soy consumed in the study, based on Max Soy Company analysis, is shown in Table 1.

The participants in the TSP group were instructed on the preparation of their TSP meal. First, they have to soak the TSP with warm water for about 2-3 min and drained it. Next, they have to cook the TSP with turmeric powder and lime juice for $2 \mathrm{~min}$. The prepared TSP meal was to be taken in a portion at breakfast or around mid-morning (10:00 am to 10:30 am). Lastly, they were strongly advised to completely take all the prepared TSP to avoid any possible errors in the results. Along with soy-nut and TSP bags, the participants were also given graduated beakers of $100 \mathrm{ml}$ and $200 \mathrm{ml}$ for estimating the quantity of soy-nut and TSP to be consumed, retrospectively.

Table 1 Nutrient composition of soy used in the study

\begin{tabular}{lll}
\hline Nutrients/35 g & Soy-nut & TSP \\
\hline Energy (Kcal) & 176 & 122 \\
Protein (g) & 13.8 & 18.2 \\
Fat (g) & 8.7 & 0.45 \\
Total carbohydrate (g) & 11.5 & 11.4 \\
Fiber (g) & 11.9 & 10.5 \\
Sodium (mg) & 11.9 & 10.5 \\
Calcium (mg) & 54.6 & 46.5 \\
Magnesium (mg) & 50.7 & 47.1 \\
Potassium (mg) & 514.5 & 427.5 \\
Isoflavones (mg) & 117.2 & 96.2 \\
Diadzein (mg) & 47.6 & 38.5 \\
Genistein (mg) & 60.2 & 48.8 \\
Glycitein (mg) & 9.45 & 8.9 \\
\hline
\end{tabular}

TSP: Textured soy protein 
The daily diet and physical activity habits of the participants remained unchanged as the research was directed towards the effects of soy on metabolic indices of the human body. Compliance to soy consumption was monitored by asking participants to return the soy bags. The returned bags were weighted to measure the remaining soy, if any. Adherence was also monitored by regular attendance at the bi-weekly meetings and by monthly analysis of 3-day food records and physical activity questionnaire. All participants provided three physical activity records (for the last 7 days of each month) and three dietary records (for three consecutive days on study weeks) to ensure that they maintained their usual diet and physical activity during the intervention. Both dietary and physical activity records were taken at weeks 4, 8 and 12 of the intervention (Fig. 1). Food intake analyzed by Nutritionist IV software (First Databank, San Bruno, CA).

\section{Outcomes}

In this study, the primary outcome was the changes from the baseline in lipid profile [total cholesterol (TC), low density lipoprotein (LDL-C), very low density lipoprotein (VLDL-C),HDL-C, TG, apolipoprotein B100 (Apo B100) and apolipoprotein AI (APO AI), glycemia status [FBG, serum insulin, homeostasis model of assessment insulin resistance (HOMA-IR), TG/HDL], oxidative stress [malondialdehyde (MDA), total antioxidant capacity (TAC)], C-reactive protein (CRP), fibrinogen, also waist circumference (WC), triceps skin fold (TSF), systolic blood pressure (SBP) and diastolic blood pressure (DBP). Fasting blood samples were obtained at the baseline and study endpoint at the Biochemical Research Laboratory of the BUMS in an early morning after an overnight $12-\mathrm{h}$ fast.
Three fully- skilled specialists did all blood sample analyses in the biochemical research laboratory of the BUMS. Each specialist was responsible for a specific blood profile analysis; lipid and glucose analysis, Elisa test (Apo AI, Apo B100, CRP, insulin), and TAC and MDA tests. Ten $\mathrm{ml}$ of venous blood was drawn; $1.8 \mathrm{ml}$ of the blood samples was collected in citrated tubes for measuring fibrinogen. The rest of the blood samples were collected into test tubes. Blood samples were left at room temperature until they clotted. Clots were gently separated from the tubes by use of a wooden applicator and then the blood samples were centrifuged for $10 \mathrm{~min}$ at $2000 \mathrm{rpm}$ to obtain the serum samples, within 15 min of collection. Serum samples were separated into microtubes and then they were frozen at $-80^{\circ} \mathrm{C}$ until further analysis.

Fasting serum TC and TG concentrations were measured using Elitech kit from France, LDL-C, HDL-C, VLDL-C and FBG by Pars Azmoon kit from Iran. The lipid profiles and FBG were assayed on Mindray-BS 300, chemistry Autoanalyzer (Mindray-BS 300, Nanshan, Shenzhen, China). TG/HDL-C Ratio was calculated and used as an indicator of insulin resistance. To determine serum apoB100, apoAI, insulin and hs-CRP concentrations, we used ELISA kits (Diagnostic Mabteck $\mathrm{AB}$, Sweden, DiaPlus Canada Inc, Montreal, Canada and AccuBind ELISA Kit, Monobind Inc., Costa Mesa, USA, respectively). The homeostasis model of assessment insulin resistance (HOMA-IR) was determined based on suggested formulas [35]. Fibrinogen was measured $1 \mathrm{~h}$ after sampling using MAHSA-YARAN kit from Iran, through quantitative determination of plasma fibrinogen based on Clauss method (clotting method) (WHO, 1985). MDA as direct marker of systemic oxidative stress and peroxidation lipid was evaluated by TBARS method (thiobarbituric acid reactive substances) according to the method

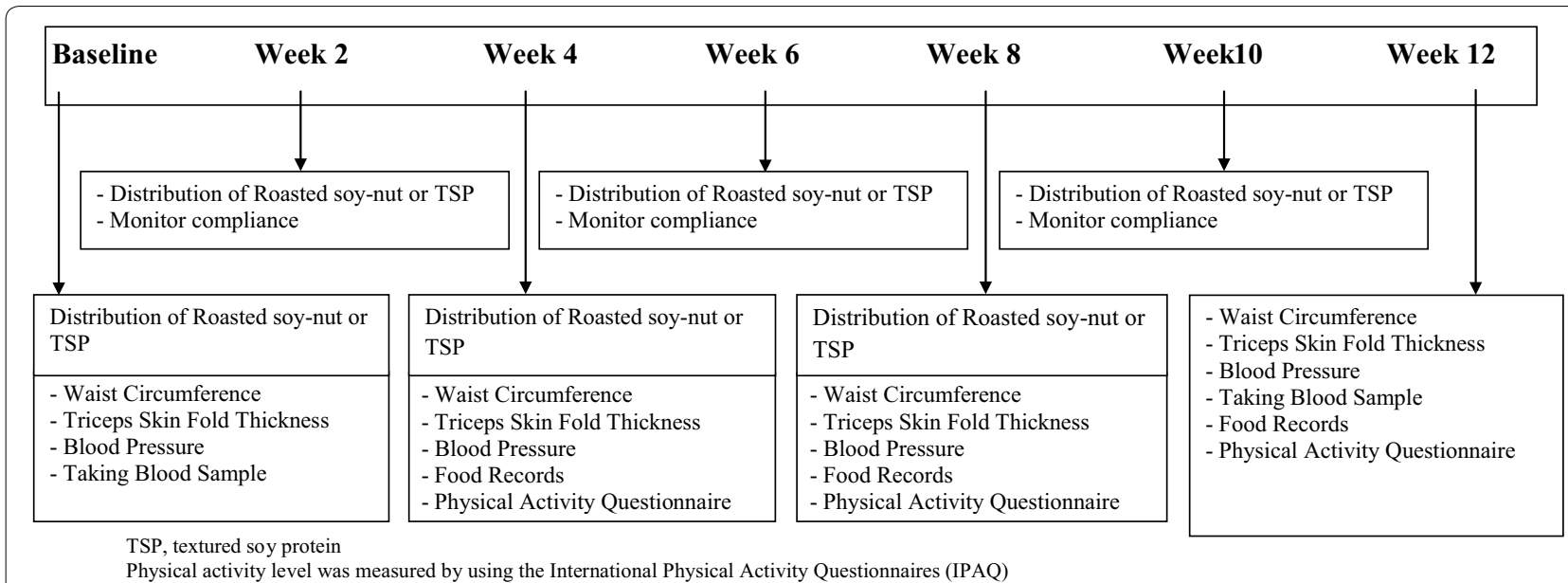

Fig. 1 Data collection schedule during 12-week intervention period 
of Ruiz-Ramos et al. [36]. Plasma TAC was quantified by using the FRAP method modified by Benzie and Strain [37].

For measuring the weight, a SECA Digital Scale (SECA, British Indicators Ltd., United Kingdom) was applied, which was calibrated with $1 \mathrm{~kg}$ of known weight and with the accuracy of $100 \mathrm{~g}$. For weight, participants were requested to wear normal light clothes. Standing position of participants during weight and height measurement was straight. Participants were requested to take off their shoes for weight and height measures to be accurate [38]. For height measurement, participants stood upright on the board of the stadiometer while their back positioned to the vertical background of the stadiometer [38]. BMI was calculated as weight (in $\mathrm{kg}$ ) divided by height in meters squared [38].

WC was measured as the width between the bottom rib and the top of the hip of the participants using a metric measuring tape in standing position. TSF was measured by a skinfold caliper (Pooyaye Armaghan Co., Iran) at the upper arm mid-point mark on the posterior surface of the right upper arm between the acromion process of scapula and the olecranon process. Middle point was marked with the elbow flexed at $90^{\circ}$ and measurement of the thickness of a fold of skin and the underlying subcutaneous tissue was made with the arm hanging loosely at the side of the body with the skinfold caliper Blood pressure was analyzed using the ALPK2 Aneroid model, Sphygmomanometer, (Tanaka Sangyo, Co. LTD. Tokyo, Japan). The secondary outcome included soy intervention complications (most complaints include soy allergies, mild constipation, nausea, bloating, burning and stomach ache), participants' compliance, and soy tolerance and comparison in the two groups.

\section{Statistical analysis}

Normality of variables of interest was tested by Kolmogorov-Smirnov. To detect differences in general characteristics, dietary intakes and physical activity in the groups, we used $X^{2}$ and ANOVA test. To determine the effects of soy administration on markers of lipid profile, apoB100 and $\mathrm{AI}$, glucose intolerance, oxidative stress, CRP, fibrinogen, also WC, TSF and blood pressure, we used one-way repeated measures analysis of variance. Withingroup comparisons (endpoint vs. baseline) were done based on the paired-samples $t$ test. Analysis of Covariance (ANCOVA) was also run to determine the effect of the intervention on the treatment groups after removing the variances for pre-treatment levels of the variables. The Generalized Linear Model (GLM) repeated measures analysis, two factor mixed design was applied to detect the changes in mean of the WC, TSF, SBP and DBP of the participants during the 12-week intervention. Statistical analysis was performed using SPSS version 17 software (SPSS Inc., Chicago, IL). The two-tailed $\mathrm{p}$ value less than 0.05 were considered significant.

\section{Results}

All participants completed the entire study. We found that, the rate of compliance in the present study was high, as more than $90 \%$ of soy bags were taken throughout the study in both groups intervention. Both the soy-nut and TSP were well tolerated. There was no serious complaint on the consumption of soy except for the cause of flatulence in five of the participants in the TSP group.

Baseline characteristics of the participants are presented in Table 2. The participants did not have significant differences with regard to any baseline variables, as well as in terms of dietary intakes and physical activity throughout the intervention. Results of the food record analysis are presented in Additional file 1: Table S1. After having taken out the energy and fiber from the soy supplementations, there were no significant differences in energy, protein, carbohydrate, saturated fat, monounsaturated fat, polyunsaturated fat and dietary fiber among the three groups at baseline and after intervention. As well as mean of dietary intake of the participants during the 12-week intervention was reported in Additional file 1: Table S2. Additional file 1: Table S3 shows different domains of physical activity of the participants according to international physical activity questionnaire (IPAQ) at baseline and after intervention. There was no significant difference in physical activity level at the baseline and after intervention in the groups.

Table 2 Baseline participants' characteristics ${ }^{a}$

\begin{tabular}{llll}
\hline Variables & $\begin{array}{l}\text { Soy-nut } \\
(\mathbf{n = 7 5 )}\end{array}$ & $\begin{array}{l}\text { TSP } \\
(\mathbf{n = 7 5 )}\end{array}$ & $\begin{array}{l}\text { Control } \\
(\mathbf{n}=\mathbf{7 5})\end{array}$ \\
\hline Age (years) & $63.8 \pm 2.82$ & $64.6 \pm 2.91$ & $64.1 \pm 2.81$ \\
Age of menopause (years) & $48.2 \pm 3.91$ & $47.7 \pm 4.72$ & $48.6 \pm 3.62$ \\
Currently in menopause (years) & $15.5 \pm 3.64$ & $16.8 \pm 61$ & $15.5 \pm 3.75$ \\
SBP (mm Hg) & $127.3 \pm 4.41$ & $127.6 \pm 4.48$ & $127.4 \pm 4.64$ \\
DBP (mm Hg) & $79.4 \pm 6.47$ & $80.6 \pm 4.34$ & $81.4 \pm 6.15$ \\
Live with & & & $2(8)$ \\
Alone & $4(16)$ & $2(8)$ & $20(80)$ \\
Husband & $19(76)$ & $19(76)$ & $3(12)$ \\
Children & $2(8)$ & $4(16)$ & $2(8)$ \\
Economic status & & & $23(92)$ \\
Dependent & $2(8)$ & $1(4)$ & $24(96)$
\end{tabular}

TSP: Textured soy protein; SBP: systolic blood pressure; DBP: diastolic blood pressure; BMI: body mass index

Obtained from ANOVA and $x^{2}$ test

a Values are mean \pm SD or numbers of participants (percentages) 
After 12 weeks of intervention, the participants who received soy-nut had significantly decreased TC ( $\mathrm{p}<0.001)$, LDL-C $(\mathrm{p}<0.05)$, VLDL-C $(\mathrm{p}<0.05)$, apoB100 $(\mathrm{p}<0.05)$, FBG $(\mathrm{p}<0.05)$, insulin $(\mathrm{p}<0.05)$, HOMAIR $(\mathrm{p}<0.01)$, MDA $(\mathrm{p}<0.01)$ levels and a significantly increased in TAC $(\mathrm{p}<0.01)$ level compared with the control group. At the same time, the TSP decreased significantly TC $(\mathrm{p}<0.05)$, insulin $(\mathrm{p}<0.05)$, MDA $(\mathrm{p}<0.05)$ levels and a significant increase in TAC $(\mathrm{p}<0.05)$ level. We did not find significant effects of soy consumption, on apo AI, TG, HDL-C, TG/HDL, CRP and fibrinogen levels after intervention (Table 3). Mean changes within groups showed significant inter-individual changes for all variables of lipid profiles; glycemia status $(\mathrm{p}<0.001)$ and oxidative stress $(\mathrm{p}<0.001)$ markers in both intervention groups $(\mathrm{p}<0.001)$. The soy-nut group experienced more changes, though the changes were not significant between intervention groups on the blood markers except for glycemiamarkers (Table 4). After adjusting for blood biomarkers baseline values by Analysis of Covariance, the results remained constant.

Post-hoc GLM repeated measures, did not show any significant effect over time on weight $(p=0.19)$, BMI $(p=0.16)$, WC $(p=0.84), \operatorname{TSF}(p=0.97), \operatorname{SBP}(p=0.87)$ and DBP $(\mathrm{p}=0.07)$ in the intervention groups or the control group (Figs. 2, 3, 4, 5, 6 and 7).

\section{Discussion}

The results of our study indicate that soy consumption improves the metabolic status of elderly women. These improvements were more visible in the soy-nut group. However, clinical indices did not show any significant difference between intervention groups and control group. There are many studies on the health effects of soy [12, $19,20,34,39]$, but only few studies described the use of two types of soy at the same time, on several components of MetS and they often have different outcome or methods $[10,14,17]$.

Our study shows that receiving both types of soy for 12 weeks resulted in a significant decrease in lipid profile compared with the control group; except for HDL-C and TG. The results of this intervention are consistent with the results of several comprehensive reviews on soy consumption and cardiovascular health [13, 14, 39-42]. All these reports concluded that there was a significant effect of roasted soy-nut and soy protein containing isoflavones on LDL-C, TC, apoB100, but not on HDL-C and TG concentrations, when consumed at levels similar to this study. However, among some previous reports, only a few studies observed significant changes in the HDL-C level [43]. Their studies showed that the highest effects of soy protein on TC and LDL-C occurred within the short-term period of intervention, whereas improvement

Tables 3 Metabolic status at the baseline and end of trial

\begin{tabular}{|c|c|c|c|c|c|c|c|c|}
\hline \multirow[t]{2}{*}{ Metabolic indicators } & \multicolumn{4}{|l|}{ Baseline } & \multicolumn{4}{|l|}{ End of trial } \\
\hline & Soy-nut & TSP & Control & $P$ value & Soy-nut & TSP & Control & $P$ value \\
\hline $\mathrm{TC}(\mathrm{mg} / \mathrm{dl})$ & $229.9 \pm 5.13$ & $229.4 \pm 5.84$ & $233.2 \pm 5.20$ & 0.87 & $200.7 \pm 4.82^{a}$ & $205.2 \pm 5.55^{\mathrm{a}}$ & $224.5 \pm 5.21$ & $<0.001$ \\
\hline $\mathrm{TG}(\mathrm{mg} / \mathrm{dl})$ & $212.1 \pm 8.23$ & $211.9 \pm 8.86$ & $212.6 \pm 10.65$ & 0.99 & $199.8 \pm 8.65$ & $200.3 \pm 9.09$ & $208.5 \pm 10.79$ & 0.77 \\
\hline HDL-C (mg/dl) & $44.2 \pm 1.38$ & $43.0 \pm 0.98$ & $44.2 \pm 1.58$ & 0.78 & $46.3 \pm 1.17$ & $44.8 \pm 0.93$ & $43.7 \pm 1.71$ & 0.35 \\
\hline LDL-C (mg/dl) & $154.0 \pm 3.28$ & $154.7 \pm 5.80$ & $152.3 \pm 6.01$ & 0.95 & $131.0 \pm 5.42^{\mathrm{a}}$ & $134.5 \pm 5.65$ & $151.5 \pm 6.51$ & $<0.05$ \\
\hline VLDL-C (mg/dl) & $41.7 \pm 1.56$ & $42.4 \pm 1.77$ & $42.4 \pm 2.19$ & 0.95 & $34.5 \pm 1.83^{\mathrm{a}}$ & $37.4 \pm 2.03$ & $42.0 \pm 2.28$ & $<0.05$ \\
\hline Apo Al (g/l) & $1.8 \pm 0.20$ & $1.7 \pm 0.22$ & $1.6 \pm 0.22$ & 0.77 & $2.0 \pm 0.19$ & $1.9 \pm 0.22$ & $1.6 \pm 0.21$ & 0.31 \\
\hline Apo $B_{100}(g / l)$ & $1.5 \pm 0.09$ & $1.5 \pm 0.10$ & $1.5 \pm 0.17$ & 0.96 & $1.2 \pm 0.07^{\mathrm{a}}$ & $1.2 \pm 0.09$ & $1.6 \pm 0.16$ & $<0.05$ \\
\hline $\mathrm{FBG}(\mathrm{mg} / \mathrm{dl})$ & $104.8 \pm 2.01$ & $104.3 \pm 2.32$ & $102.5 \pm 2.49$ & 0.75 & $90.4 \pm 2.18^{a}$ & $97.8 \pm 2.34$ & $99.6 \pm 2.83$ & $<0.05$ \\
\hline Insulin $(\mu|\bigcup / m|)$ & $12.8 \pm 0.79$ & $11.6 \pm 0.95$ & $13.4 \pm 0.9$ & 0.36 & $10.8 \pm 0.79^{a}$ & $10.8 \pm 0.85^{\mathrm{a}}$ & $13.8 \pm 0.90$ & $<0.05$ \\
\hline HOMA-IR & $3.4 \pm 0.25$ & $3.0 \pm 0.27$ & $3.4 \pm 0.25$ & 0.51 & $2.5 \pm 0.21^{\mathrm{a}}$ & $2.6 \pm 0.23$ & $3.4 \pm 0.24$ & $<0.01$ \\
\hline $\mathrm{TG} / \mathrm{HDL}$ & $4.9 \pm 0.27$ & $5 \pm 0.25$ & $4.9 \pm 0.34$ & 0.99 & $4.41 \pm 0.24$ & $4.5 \pm 0.24$ & $5 \pm 0.39$ & 0.35 \\
\hline $\operatorname{CRP}(\mu \mathrm{g} / \mathrm{ml})$ & $3.2 \pm 0.37$ & $3.1 \pm 0.45$ & $3.0 \pm 0.49$ & 0.97 & $2.9 \pm 0.38$ & $3.0 \pm 0.39$ & $3.0 \pm 0.33$ & 0.98 \\
\hline Fibrinogen (mg/dl) & $316.7 \pm 6.89$ & $316.5 \pm 8.88$ & $314.2 \pm 9.37$ & 0.97 & $297.8 \pm 6.07$ & $302.0 \pm 6.37$ & $306.4 \pm 6.59$ & 0.63 \\
\hline MDA ( $\mu \mathrm{mol} / \mathrm{l})$ & $4.9 \pm 0.36$ & $4.9 \pm 0.17$ & $5.3 \pm 0.28$ & 0.48 & $4.2 \pm 0.35^{a}$ & $4.3 \pm 0.19^{a}$ & $5.3 \pm 0.25$ & $<0.001$ \\
\hline $\mathrm{TAC}(\mu \mathrm{mol} / \mathrm{l})$ & $1302.0 \pm 45.36$ & $1305.3 \pm 45.37$ & $1305.1 \pm 40.09$ & 0.99 & $1516.3 \pm 39.70^{a}$ & $1503.4 \pm 35.28^{a}$ & $1350.2 \pm 47.38$ & $<0.01$ \\
\hline
\end{tabular}

TSP: Textured soy protein; SBP: systolic blood pressure; DBP: diastolic blood pressure; TC: total cholesterol; TG: triglyceride; HDL-C: high density lipoprotein; LDL-C: low density lipoprotein; VLDL-C: very low density lipoprotein; Apo Al: apolipoprotein Al; Apo B100: apolipoprotein B100; FBG: fasting blood glucose; HOMA-IR: homeostasis model of assessment insulin resistance; TG/HDL-C: triglyceride/high density lipoprotein; MDA: malondialdehyde; TAC: total antioxidant capacity; CRP: C-reactive protein

Values are mean \pm standard error

a There was a significant difference in the treatment groups compared with control group (post hoc ANOVA) 
Tables 4 Mean changes in metabolic indicators at the baseline and end of trial

\begin{tabular}{|c|c|c|c|c|}
\hline \multirow[t]{2}{*}{ Metabolic indicators } & \multicolumn{4}{|l|}{ Mean change } \\
\hline & Soy-nut & TSP & Control & $P$ value \\
\hline $\mathrm{TC}(\mathrm{mg} / \mathrm{dl})$ & $-29.2 \pm 3.56^{\mathrm{a}, \mathrm{c}}$ & $-24.3 \pm 3.54^{\mathrm{a}, \mathrm{c}}$ & $-8.7 \pm 5.47$ & $<0.01$ \\
\hline $\mathrm{TG}(\mathrm{mg} / \mathrm{dl})$ & $-12.2 \pm 1.86^{c}$ & $-11.6 \pm 1.95^{c}$ & $-4.1 \pm 1.12$ & 0.14 \\
\hline $\mathrm{HDL}-\mathrm{C}(\mathrm{mg} / \mathrm{dl})$ & $2.1 \pm 0.49^{c}$ & $1.7 \pm 0.64^{c}$ & $-0.57 \pm 1.46$ & 0.10 \\
\hline LDL-C (mg/dl) & $-23.1 \pm 2.03^{a, c}$ & $-20.1 \pm 3.00^{\mathrm{a}, \mathrm{c}}$ & $-0.80 \pm 3.84$ & $<0.001$ \\
\hline VLDL-C (mg/dl) & $-7.1 \pm 1.11^{\mathrm{a}, \mathrm{c}}$ & $-5.0 \pm 0.67^{a, c}$ & $-0.37 \pm 1.23$ & $<0.001$ \\
\hline Apo Al (g/l) & $0.19 \pm 0.03^{a, c}$ & $0.18 \pm 0.03^{a, c}$ & $-0.02 . \pm 0.01$ & $<0.01$ \\
\hline $\mathrm{Apo}_{100}(\mathrm{~g} / \mathrm{l})$ & $-0.31 \pm 0.04^{\mathrm{a}, \mathrm{c}}$ & $-0.28 \pm 0.01^{a, c}$ & $0.06 \pm 0.05$ & $<0.001$ \\
\hline $\mathrm{FBG}(\mathrm{mg} / \mathrm{dl})$ & $-14.4 \pm 1.10^{\mathrm{b}, \mathrm{c}}$ & $-6.5 \pm 0.60^{c}$ & $-2.8 \pm 1.54$ & $<0.001$ \\
\hline Insulin ( $\mu \mid \mathrm{U} / \mathrm{ml})$ & $-2.0 \pm 0.29^{b, c}$ & $-0.8 \pm 0.20^{\mathrm{a}, \mathrm{c}}$ & $0.4 \pm 0.22$ & $<0.001$ \\
\hline HOMA-IR & $-0.9 \pm 0.08^{\mathrm{b}, \mathrm{c}}$ & $-0.4 \pm 0.06^{\mathrm{a}, \mathrm{c}}$ & $-0.02 \pm 0.07$ & $<0.001$ \\
\hline $\mathrm{TG} / \mathrm{HDL}$ & $-0.5 \pm 0.08^{a, c}$ & $-0.4 \pm 0.09^{a, c}$ & $0.03 \pm 0.21$ & $<0.01$ \\
\hline CRP $(\mu \mathrm{g} / \mathrm{ml})$ & $-0.25 \pm 0.16$ & $-0.16 \pm 0.17$ & $-0.04 \pm 0.32$ & 0.8 \\
\hline Fibrinogen (mg/dl) & $-18.8 \pm 8.98$ & $-14.5 \pm 9.53$ & $-7.8 \pm 6.24$ & 0.65 \\
\hline MDA $(\mu \mathrm{mol} / \mathrm{l})$ & $-0.75 \pm 0.04^{\mathrm{a}, \mathrm{c}}$ & $-0.63 \pm 0.07^{a, c}$ & $-0.01 \pm 0.08$ & $<0.001$ \\
\hline TAC $(\mu \mathrm{mol} / \mathrm{l})$ & $214.2 \pm 20.02^{\mathrm{a}, \mathrm{c}}$ & $198.0 \pm 23.47^{a, c}$ & $45.1 \pm 19.34$ & $<0.001$ \\
\hline
\end{tabular}

Values are mean \pm standard error

TSP: Textured soy protein; SBP: systolic blood pressure; DBP: diastolic blood pressure; TC: total cholesterol; TG: triglyceride; HDL-C: high density lipoprotein; LDL-C: low density lipoprotein; VLDL-C: very low density lipoprotein; Apo Al: apolipoprotein Al; Apo B100: apolipoprotein B100; FBG: fasting blood glucose; HOMA-IR: homeostasis model of assessment insulin resistance; TG/HDL-C: triglyceride/high density lipoprotein; MDA: malondialdehyde; TAC: total antioxidant capacity; CRP: C-reactive protein

a There was a significant difference in the treatment groups compared with control group (post hoc ANOVA)

b There was a significant difference in the soy-nut group compared with TSP and control groups (post hoc ANOVA)

c For significant changes after-before (paired t-test)

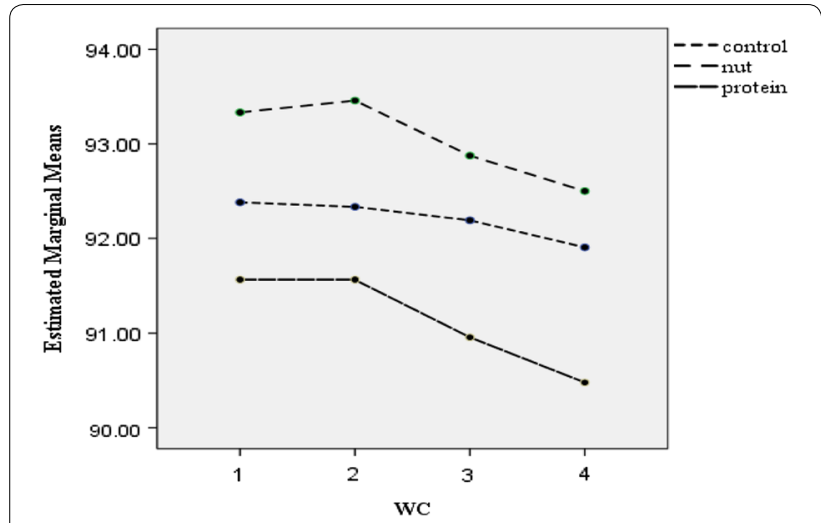

Fig. 2 Waist circumference mean for intervention and control groups by time interaction

in HDL-C was observed, only in long- term period, i.e. more than 12 weeks.

Lipid reduction mechanisms are attributed to several components in soybean including trypsin inhibitors, phytic acid, saponins, aglyconegenistein, fiber, soy storage protein (namely, the globulins $11 \mathrm{~S}$ and $7 \mathrm{~S}$ ), fatty acid predominantly unsaturated fat and specific amino acid profile (higher ratio of arginine to lysine) [11, 44]. However, some researchers attributed the beneficial effects of soybean on lipid profile to the isoflavone content, while others to soy protein and other soy components [43, 45]. These components may be altered by the processing method of the soy products. The more effects of soy-nuts than TSP on lipids can be related to higher isoflavone levels (Table 1), as well as polyunsaturated fatty acid (PUFA) and some trace components (Additional file 1: Table S2). Frying and texturization, leads to a significant decrease of isoflavone, but interestingly, Messina [11] showed processing of the soy products appeared to have had little effect on their influence on lipid.

Beneficial effects of soy-nut and TSP on glycemia status were also shown in this study. Health benefits of soy on glycemic control have been reported in the most studies on animal models [7, 8]. Epidemiologic studies also explained similar results $[16,46]$; however, results from human intervention studies were not compatible [34, 47]. Improvement in blood glucose, insulin secretion and HOMA-IR has been reported in postmenopausal women with abdominal obesity [48], with insulin resistance [15] and or in healthy postmenopausal women [44], as well as in a group of adult men and women with Type 2 diabetes $[49,50]$, whereas this was not observed in some studies $[26,47]$. One explanation of this lack of benefit could be 


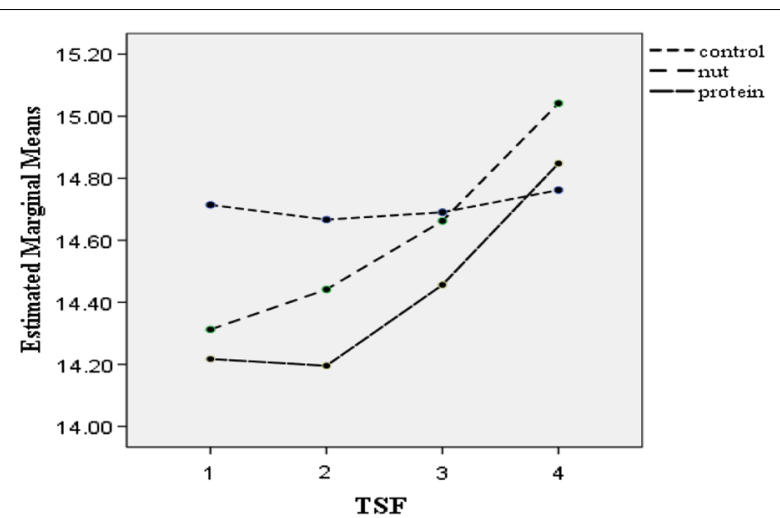

Fig. 3 Triceps skin fold mean for intervention and control groups by time interaction

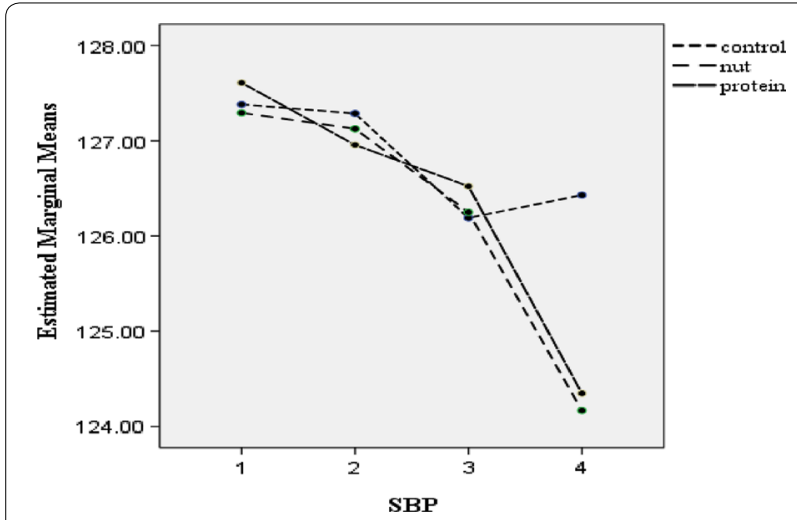

Fig. 4 Systolic blood pressure mean for intervention and control groups by time interaction

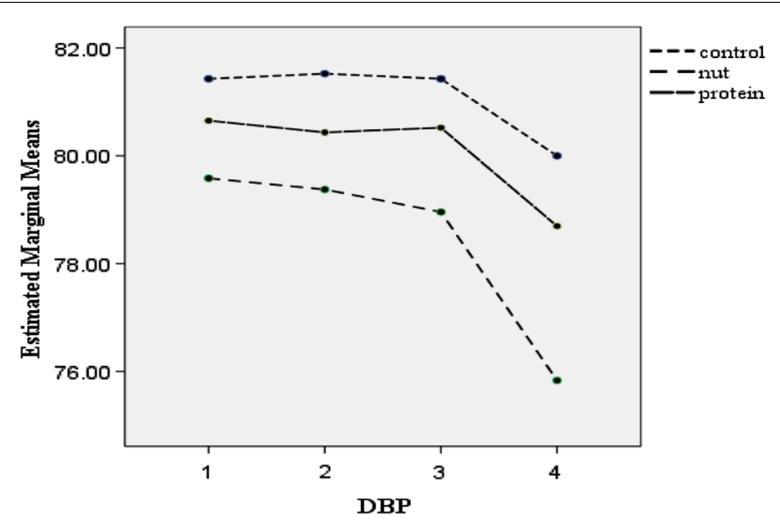

Fig. 5 Diastolic blood pressure mean for intervention and control groups by time interaction

related to the study design. In many non-effective trials, the participants were healthy. Previous evidence on the beneficial effects of soy on serum lipid has shown that soy consumption leads to decrease level of serum lipid only in hyperlipidemic patients and not healthy participants [13]. It can be concluded that no significant effect on glycemic control markers in healthy subject may have been due to normal levels of these markers at the baseline.

Soybean is rich in soluble fiber, tannins, phytates, and genistein, all of which inversely correlate with carbohydrate digestion and glycemic response. Soybean intake also reduces the risk of developing diabetes in the same way it protects against obesity; because it is high in fiber, low in fat, and has low glycemic index [51]. In the current study, the improvement in FBG, insulin and HOMA-IR after the active treatment in the roasted soy-nut group without a change in weight is independent of the action of soy fiber that enhances the feeling of satiety and thus causes an improvement in insulin resistance secondary to weight loss. Soy-nut has a lower glycemic index than TSP, because of the higher phytate and fiber content [52].

In the present study, the participants were in a chronic inflammatory state $(\mathrm{CRP} \geq 3 \mu \mathrm{g} / \mathrm{ml})$. The findings of this study showed that the consumption of either roasted soy-nut or TSP had no significant effect on the concentration of CRP. This result is consistent with several studies investigating the role of different types of tree nuts, peanut, and soy nut consumption [17], soy protein consumed through soy based foods $[53,54]$ or extracted isoflavones [26] on CRP in postmenopausal women and middle-age men and women. In contrast, some studies did observe a significant decrease in serum CRP, one of which included 104 obese diabetic patients using glucose lowering drugs who consumed a dietary soy supplement for 12 month [55]. Another one included 41 Type 2 diabetic patients with nephropathy who consumed TSP for 4 years [18] and Liu et al. [56] examined the effect of whole soy (soy flour) and purified daidzein on postmenopausal women who were equol producers for 6 month. The inconsistency between those studies could be due to differences in the study samples, such as equol producers or use of medications, as these studies included subjects who had diabetic complications, compared to the participants in the current study who were free from secondary MetS complications and did not use any glycemic or lipid-lowering medications.

Studies on the effects of soy on fibrinogen are limited. However, the lack of significant effect of soy consumption on serum fibrinogen in the current study is consistent with the majority of previous studies that have examined the effect of soy for time periods ranging from 4 weeks to 6 months in 47 healthy postmenopausal women [20], 69 mildly hypercholesterolemia perimenopausal women [25] and 20 Type 2 diabetic subjects [57] or 20 young healthy normolipidemic subjects [58]. Only one of the previous studies of 389 osteopenic, postmenopausal 


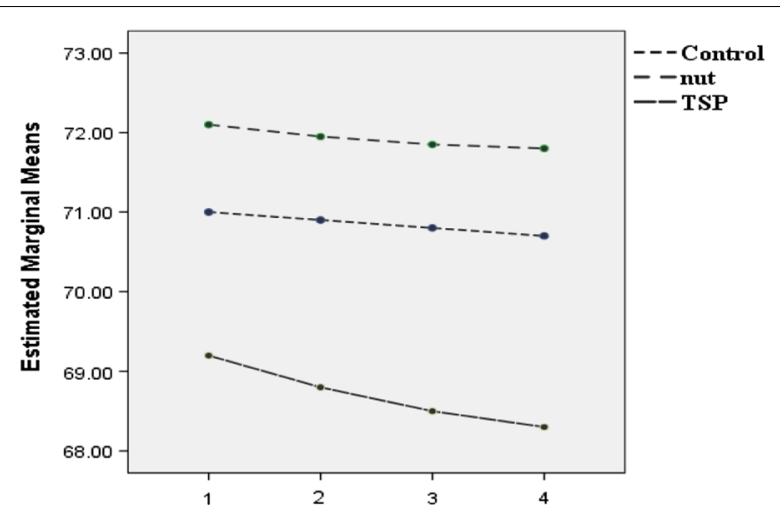

- Four measurements including baseline, weeks 4, 8, and 12 values. - Obtained from GLM Repeated test.

Fig. 6 Weight mean for intervention and control groups by time interaction

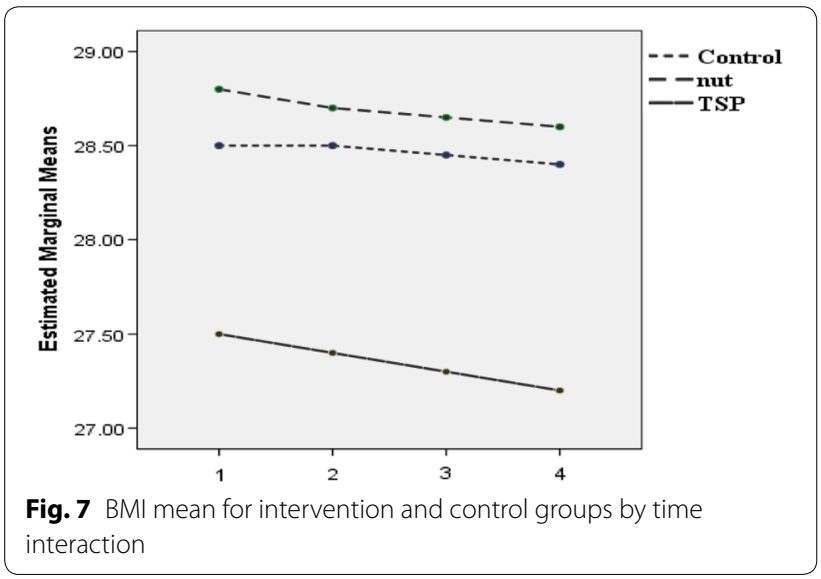

women has reported the significant decrease of fibrinogen with soy isoflavone supplement intake. They found that daily intake of $54 \mathrm{mg}$ genisteinplus calcium, vitamin D3, and a healthy diet for 24 months resulted in a significant reduction in serum fibrinogen [19]. The reason of the difference may be because of long-term intervention.

The beneficial effects of both types of soy on TAC and MDA as indicators of lipid peroxidation and antioxidant activity were shown in this study. The compounds in soybean with antioxidant properties including flavonoids, isoflavones (genistein and daidzein), tri-terpenoids, carotenoids, tocopherols, and saponins may protect against lipid oxidation and improve total antioxidant status [59]. Linoleic acid is also a predominant fatty acid of soy food and has specific effects on eicosanoid synthesis and metabolism and lipid peroxidation [60].

The health benefits of soy on suppressing LDL oxidation by genistin were shown in vitro and animal studies $[9,10,12]$. Human-based results were controversial.
Fritz et al. [61] examined antioxidant effect of three levels of isoflavones among women. Soy leads to increase in antioxidant activity regardless of the level of isoflavone consumed. Swain et al. [62] also showed that the consumption of soy protein could affect TAC plasma after 12 weeks. The study among diabetic retinopathy patients showed reduced levels of lipid oxidation by daily supplementation of $120 \mathrm{mg}$ of genistein and $57 \mathrm{mg}$ of daidzein, for 12 weeks [21]. In contrast, some studies did not observe significant improvement in oxidative stress markers. One of which included 25 type 2 diabetic patients with nephropathy who consumed soy milk supplement for 4 weeks [22] and the other which included 43 oophorectomized women who consumed $75 \mathrm{mg} /$ day isoflavones tablet for 12 weeks [52]. The inconsistency between studies could be due to the form in which soy was provided. The isoflavones in soy milk are mainly hydrophilic ß-glycoside conjugates and therefore, faster absorption rates and earlier peak serum concentrations are expected for all subjects given soy milk compared with the solid soy food matrix of TSP [63].

Researchers believed that antioxidant activity of soy may be due to its phytoestrogen or high phytic acid content [59]. The phytate in soy may quench free radicals because of its metal chelating ability [64]. Nevertheless, Engelman et al. [65] showed that neither isoflavones nor phytate in soy protein isolate had a significant effect in reducing oxidative damage. According to the results, despite the higher phytoestrogen content of roasted soynut, both soy types caused a significant improvement on MDA and TAC indicators. It seems that processing of the soy products appeared to have little effect on their influence on oxidative stress markers.

The lack of a significant effect in clinical indices including WC, TSP, SBP and DBP in the current study is consistent with the majority of studies carried out among postmenopausal women that have examined the effect of soy for time periods ranging from 12 weeks to 12 months and observed no significant reduction in anthropometric measurements $[24,27,66]$. In contrast, some others reported significant reduction on weight, BMI and WC [67-69]. The reason for this difference could be due to the simultaneous use of lifestyle improvement programs and the presence of subjects in different age and gender groups.

This study may have some limitations. First, we did not include a placebo in the study since the participants in the treatment groups were consuming natural soy products, not soy supplement pills. It was impossible to apply any placebo for the control group. Second, we attempted to follow the participants and used a dietary and physical activity record. However, dietary assessment might have some biases. Third, we could not measure serum 
or urine isoflavones levels, which could be a limitation of this study. The inclusion of only subjects with no need for medication is a strength point of this study, because it allowed for focusing on the potential of soy to act as a prevention strategy, to possibly prevent or delay the need for pharmaceutical treatment. Our participants had a kind of homogeneity in sex, age and health conditions, too. Also we have a high compliance of participants who completed this study. Considering, the use of two types of soy (natural and processed form), and the effects of both kinds in improving MetS' features, can help us in providing different types of soy products according to people's taste.

\section{Conclusion}

This study showed the beneficial effect of soy in elderly women with borderline parameters of MetS who suffered from a hyperlipidemic, insulin resistance status (TG/ HDL-C $>3.5$, HOMA-IR $>2.5$ and fasting insulin $>12.5$ ) and oxidative stress $(\mathrm{MDA} \geq 5)$. Soy-nut decreases these indicators in a greater degree than TSP. The more effects of soy-nut can be due to the higher presence of some components, such as isoflavone genistein, PUFA, and some trace components, and also lower glycemic index than TSP. Therefore, inclusion of soy in their usual diet can reduce the need for medical treatment through the simultaneous improvement of multiple metabolic disorders. Another important finding is that although the manufacturing process may affect the beneficial effects of soy products, processed products, as TSP, can also provide beneficial effects for consumers.

\section{Additional file}

Additional file 1: Table S1. Estimated energy, macronutrient and fiber intakes at baseline and after the intervention in elderly women with MetS. Table S2. Mean of dietary intake of the participants during the 12-week intervention by Generalized Linear Model repeated measures. Table S3. Estimated physical activity levels at baseline and after intervention in elderly women with MetS.

\section{Abbreviations}

MetS: metabolic syndrome; TSP: textured soy protein; TC: cholesterol; TG: triglyceride; HDL-C: high density lipoprotein; LDL-C: low density lipoprotein; VLDL-C: very low density lipoprotein; Apo B100: apolipoprotein B100; APO Al: apolipoprotein Al; MDA: malondialdehyde; TAC: total antioxidant capacity; TBARS: thiobarbituric acid reactive substances; FBG: fasting blood glocuse; HOMA-IR: homeostasis model of assessment insulin resistance; CRP: C-reactive protein; WC: waist circumference; TSF: triceps skin fold; SBP: systolic blood pressure; DBP: diastolic blood pressure; GLM: Generalized Linear Model; CVD: cardiovascular disease; ROS: reactive oxygen species; IPAQ: International Physical Activity Questionnaires; BUMS: Babol University of Medical Sciences.

\section{Acknowledgements}

Cooperative attitudes of Max Soy company in providing us the soy-nut and TSP used in this study is gratefully acknowledged. We thank all of the participants in the study as well as the staff at the rural health clinics of Babol, Iran, for their cooperation in this study.

\section{Authors' contributions}

$A B$ conceived and designed the study, she also did data collection. KHT performed data analysis. He had full access to all the data in the study and takes responsibility for the integrity of the data and the accuracy of the data analysis. FNA and SO reviewed the literature, analyzed and interpreted data, drafted and prepared the manuscript. All authors read and approved the final manuscript.

\section{Funding}

This study was approved and funded by the Deputy for Research of Babol University of Medical Sciences (Grant No: 229).

\section{Availability of data and materials}

We have had access to all the data in the study (for original research articles) and accept responsibility for its validity.

\section{Ethics approval and consent to participate}

All procedures were carried out on the basis of ethics standards of the responsible committee on human experimentation (institutional and national) and to the Declaration of Helsinki. In addition, the ethics Committee of BUMS approved the study (NO.MUBABOL.REC.1388.1). All participants provided an informed written and signed consent form. All patients provided written informed consent.

\section{Consent for publication}

We confirm that the manuscript entitled "Clinical and metabolic response to soy administration in older women with metabolic syndrome: A randomized controlled trial" has been read and approved by all named authors and that there are no other persons who satisfied the criteria for authorship but are not listed. We further confirm that the order of authors listed in the manuscript has been approved by all of us. The manuscript submitted for publication in Diabetology\& Metabolic Syndrome has been read and approved by all authors, has not been published, totally or partly, in any other journal even in Persian language and if accepted for publication in this Journal, it will not be published in any other periodicals. Besides, it is confirmed that this article has not been submitted simultaneously to other journals in Iran and/or other countries. I accept the liability of the scientific integrity of the manuscript contents. We confirm that we have given due consideration to the protection of intellectual property associated with this work and that there are no impediments to publication, including the timing of publication, with respect to intellectual property. In so doing we confirm that we have followed the regulations of our institutions concerning intellectual property. We understand that the Corresponding Author is the sole contact for the Editorial process (including Editorial Manager and direct communications with the office). She is responsible for communicating with the other authors about progress, submissions of revisions and final approval of proofs.

\section{Competing interests}

The authors declare that they have no competing interests.

\section{Author details}

${ }^{1}$ Mobility Impairment Research Center, Health Research Institute, Babol University of Medical Sciences, Babol, Iran. ${ }^{2}$ Department of Biostatistics and Epidemiology, Faculty of Medicine, Babol University of Medical Sciences, Babol, Iran. ${ }^{3}$ Social Determinants of Health Research Center, Health Research Institute, Babol University of Medical Sciences, Babol, Iran. ${ }^{4}$ Infertility and Health Reproductive Research Center, Health Research Institute, Babol University of Medical Sciences, Babol, Iran. ${ }^{5}$ Department of Midwifery, Faculty of Nursing and Midwifery, Babol University of Medical Sciences, Babol, Iran.

Received: 20 January 2019 Accepted: 11 June 2019

Published online: 20 June 2019 


\section{References}

1. Xiao J, Wu CL, Gao YX, Wang SL, Wang L, Lu QY, et al. Prevalence of metabolic syndrome and its risk factors among rural adults in Nantong, China. Sci Rep. 2016;6:38089.

2. Grundy SM. Metabolic syndrome update. Trends Cardiovasc Med. 2016;26(4):364-73.

3. Broderstad AR, Melhus M. Prevalence of metabolic syndrome and diabetes mellitus in Sami and Norwegian populations. The SAMINOR-a cross-sectional study. BMJ Open. 2016;6(4):e009474.

4. Mokhayeri Y, Riahi SM, Rahimzadeh S, Pourhoseingholi MA, HashemiNazari SS. Metabolic syndrome prevalence in the Iranian adult's general population and its trend: a systematic review and meta-analysis of observational studies. Diabetes Metab Syndr. 2018;12(3):441-53.

5. Pu D, Tan R, Yu Q, Wu J. Metabolic syndrome in menopause and associated factors: a meta-analysis. Climacteric. 2017;20(6):583-91.

6. Rochlani Y, Pothineni NV, Kovelamudi S, Mehta JL. Metabolic syndrome: pathophysiology, management, and modulation by natural compounds. Ther Adv Cardiovasc Dis. 2017:11(8):215-25.

7. Zimmermann C, Cederroth CR, Bourgoin L, Foti M, Nef S. Prevention of diabetes in $\mathrm{db} / \mathrm{db}$ mice by dietary soy is independent of isoflavone levels. Endocrinology. 2012;153(11):5200-11.

8. Song S, Hooiveld GJ, Li M, Zhao F, Zhang W, Xu X, et al. Dietary soy and meat proteins induce distinct physiological and gene expression changes in rats. Sci Rep. 2016;6:20036.

9. El LM, Nh M, NI Z, Ms A, Hm S, Mohamed N. Effects of soybean isoflavone on lipid profiles and antioxidant enzyme activity in streptozotocin induced diabetic rats. Glob J Pharmacol. 2014;8(3):378-84.

10. Byun JS, Han YS, Lee SS. The effects of yellow soybean, black soybean, and sword bean on lipid levels and oxidative stress in ovariectomized rats. Int J Vitam Nutr Res. 2010;80(2):97-106.

11. Messina M. Soy and health update: evaluation of the clinical and epidemiologic literature. Nutrients. 2016;8(12):754.

12. Ramdath DD, Padhi EM, Sarfaraz S, Renwick S, Duncan AM. Beyond the cholesterol-lowering effect of soy protein: a review of the effects of dietary soy and its constituents on risk factors for cardiovascular disease. Nutrients. 2017;9(4):324.

13. Welty FK, Lee KS, Lew NS, Zhou JR. Effect of soy nuts on blood pressure and lipid levels in hypertensive, prehypertensive, and normotensive postmenopausal women. Arch Intern Med. 2007;167(10):1060-7.

14. Matthan NR, Jalbert SM, Ausman LM, Kuvin JT, Karas RH, Lichtenstein AH. Effect of soy protein from differently processed products on cardiovascular disease risk factors and vascular endothelial function in hypercholesterolemic subjects. Am J Clin Nutr. 2007;85(4):960-6.

15. Llaneza P, Gonzalez C, Fernandez-Inarrea J, Alonso A, Diaz F, Perez-Lopez FR. Soy isoflavones improve insulin sensitivity without changing serum leptin among postmenopausal women. Climacteric. 2012;15(6):611-20.

16. Mueller NT, Odegaard AO, Gross MD, Koh WP, Yu MC, Yuan JM, et al. Soy intake and risk of type 2 diabetes in Chinese Singaporeans [corrected] Eur J Nutr. 2012:51(8):1033-40.

17. Mazidi M, Rezaie P, Ferns GA, Gao HK. Impact of different types of tree nut, peanut, and soy nut consumption on serum C-reactive protein (CRP): a systematic review and meta-analysis of randomized controlled clinical trials. Medicine. 2016:95(44):e5165.

18. Azadbakht L, Atabak S, Esmaillzadeh A. Soy protein intake, cardiorenal indices, and C-reactive protein in type 2 diabetes with nephropathy: a longitudinal randomized clinical trial. Diabetes Care. 2008;31(4):648-54.

19. Atteritano M, Marini H, Minutoli L, Polito F, Bitto A, Altavilla D, et al. Effects of the phytoestrogen genistein on some predictors of cardiovascular risk in osteopenic, postmenopausal women: a two-year randomized, double-blind, placebo-controlled study. J Clin Endocrinol Metab. 2007;92(8):3068-75

20. Rios DR, Rodrigues ET, Cardoso AP, Montes MB, Franceschini SA, Toloi MR. Effects of isoflavones on the coagulation and fibrinolytic system of postmenopausal women. Nutrition. 2008:24(2):120-6.

21. Oh HY, Kim SS, Chung HY, Yoon S. Isoflavone supplements exert hormonal and antioxidant effects in postmenopausal Korean women with diabetic retinopathy. J Med Food. 2005;8(1):1-7.

22. Miraghajani MS, Esmaillzadeh A, Najafabadi MM, Mirlohi M, Azadbakht L. Soy milk consumption, inflammation, coagulation, and oxidative stress among type 2 diabetic patients with nephropathy. Diabetes Care. 2012:35(10):1981-5
23. Gobert CP, Pipe EA, Capes SE, Darlington GA, Lampe JW, Duncan AM. Soya protein does not affect glycaemic control in adults with type 2 diabetes. Br J Nutr. 2010;103(3):412-21.

24. Choquette S, Riesco E, Cormier E, Dion T, Aubertin-Leheudre M, Dionne IJ. Effects of soya isoflavones and exercise on body composition and clinical risk factors of cardiovascular diseases in overweight postmenopausal women: a 6-month double-blind controlled trial. Br J Nutr. 2011;105(8):1199-209.

25. Dent $S B$, Peterson CT, Brace LD, Swain JH, Reddy MB, Hanson KB, et al. Soy protein intake by perimenopausal women does not affect circulating lipids and lipoproteins or coagulation and fibrinolytic factors. J Nutr. 2001;131(9):2280-7.

26. Christie DR, Grant J, Darnell BE, Chapman VR, Gastaldelli A, Sites CK. Metabolic effects of soy supplementation in postmenopausal Caucasian and African American women: a randomized, placebo-controlled trial. Am 」 Obstet Gynecol. 2010;203(2):153.e1-9.

27. Liu ZM, Ho SC, Chen YM, Ho YP. A mild favorable effect of soy protein with isoflavones on body composition - a 6-month double-blind randomized placebo-controlled trial among Chinese postmenopausal women. Int J Obes. 2010:34(2):309-18.

28. Mohammadifard N, Salehi-Abargouei A, Salas-Salvadó J, Guasch-Ferré M, Humphries K, Sarrafzadegan N. The effect of tree nut, peanut, and soy nut consumption on blood pressure: a systematic review and meta-analysis of randomized controlled clinical trials. Am J Clin Nutr. 2015:101(5):966-82.

29. Koppelman SJ, Lakemond CM, Vlooswijk R, Hefle SL. Detection of soy proteins in processed foods: literature overview and new experimental work. J AOAC Int. 2004;87(6):1398-407.

30. Sciences DoHTUoM. Clinical guide the treatment of dyslipidemia. Puneh Publishing; 2015. p. 18.

31. Diabetes Research Center EaMRC. Clinical Diabetes Guide. Tehran University of Medical Sciences and Health Services: Puneh Publishing; 2015. p. 20.

32. Services DoHoTUoMSaH. Clinical guide to dealing with high blood pressure. Puneh Publishing; 2015. p. 28.

33. Liu ZM, Chen YM, Ho SC. Effects of soy intake on glycemic control: a meta-analysis of randomized controlled trials. Am J Clin Nutr. 2011:93(5):1092-101.

34. Fang K, Dong H, Wang D, Gong J, Huang W, Lu F. Soy isoflavones and glucose metabolism in menopausal women: a systematic review and meta-analysis of randomized controlled trials. Mol Nutr Food Res. 2016:60(7):1602-14.

35. Wallace TM, Levy JC, Matthews DR. Use and abuse of HOMA modeling. Diabetes Care. 2004;27(6):1487-95.

36. Ruiz-Ramos M, Vargas LA, Fortoul Van der Goes TI, Cervantes-Sandova A, Mendoza-Nunez VM. Supplementation of ascorbic acid and alphatocopherol is useful to preventing bone loss linked to oxidative stress in elderly. J Nutr Health Aging. 2010;14(6):467-72.

37. Benzie IF, Strain JJ. The ferric reducing ability of plasma (FRAP) as a measure of "antioxidant power": the FRAP assay. Anal Biochem. 1996:239(1):70-6.

38. NHANES. Anthropometry procedures manual. CDC. 2017.

39. Taku K, Umegaki K, Sato Y, Taki Y, Endoh K, Watanabe S. Soy isoflavones lower serum total and LDL cholesterol in humans: a meta-analysis of 11 randomized controlled trials. Am J Clin Nutr. 2007:85(4):1148-56.

40. Chen ST, Chen JR, Yang CS, Peng SJ, Ferng SH. Effect of soya protein on serum lipid profile and lipoprotein concentrations in patients undergoing hypercholesterolaemic haemodialysis. Br J Nutr. 2006;95(2):366-71.

41. Pipe EA, Gobert CP, Capes SE, Darlington GA, Lampe JW, Duncan AM. Soy protein reduces serum LDL cholesterol and the LDL cholesterol: HDL cholesterol and apolipoprotein B:apolipoprotein $\mathrm{A}-\mathrm{I}$ ratios in adults with type 2 diabetes. J Nutr. 2009:139(9):1700-6.

42. Jenkins DJ, Mirrahimi A, Srichaikul K, Berryman CE, Wang L, Carleton A, et al. Soy protein reduces serum cholesterol by both intrinsic and food displacement mechanisms. J Nutr. 2010;140(12):2302s-11s.

43. Zhan S, Ho SC. Meta-analysis of the effects of soy protein containing isoflavones on the lipid profile. Am J Clin Nutr. 2005;81(2):397-408.

44. Messina M. Soy foods, isoflavones, and the health of postmenopausal women. Am J Clin Nutr. 2014;100(Suppl 1):423s-30s. 
45. Jassi HK, Jain A, Arora S, Chitra R. Effect of soy proteins vs soy isoflavones on lipid profile in postmenopausal women. Indian J Clin Biochem. 2010;25(2):201-7.

46. Ding M, Pan A, Manson JE, Willett WC, MalikV, Rosner B, et al. Consumption of soy foods and isoflavones and risk of type 2 diabetes: a pooled analysis of three US cohorts. Eur J Clin Nutr. 2016;70(12):1381-7.

47. Liu ZM, Chen YM, Ho SC, Ho YP, Woo J. Effects of soy protein and isoflavones on glycemic control and insulin sensitivity: a 6-mo doubleblind, randomized, placebo-controlled trial in postmenopausal Chinese women with prediabetes or untreated early diabetes. Am J Clin Nutr. 2010;91(5):1394-401.

48. van Nielen M, Feskens EJ, Rietman A, Siebelink E, Mensink M. Partly replacing meat protein with soy protein alters insulin resistance and blood lipids in postmenopausal women with abdominal obesity. J Nutr. 2014;144(9):1423-9.

49. Shahbazian H, Reza A, Javad S, Heshmatollah S, Mahmood L, Ali A, et al. Beneficial effects of soy protein isoflavones on lipid and blood glucose concentrations in type 2 diabetic subjects. Saudi Med J. 2007;28(4):652-4.

50. Tatsumi Y, Morimoto A, Deura K, Mizuno S, Ohno Y, Watanabe S. Effects of soybean product intake on fasting and postload hyperglycemia and type 2 diabetes in Japanese men with high body mass index: the Saku Study. J Diabetes Investig. 2013;4(6):626-33.

51. Esmaillzadeh A, Kimiagar M, Mehrabi Y, Azadbakht L, Hu FB, Willett WC. Dietary patterns, insulin resistance, and prevalence of the metabolic syndrome in women. Am J Clin Nutr. 2007;85(3):910-8.

52. Blair RM, Henley EC, Tabor A. Soy foods have low glycemic and insulin response indices in normal weight subjects. Nutr J. 2006:5:35.

53. Ryan-Borchers TA, Park JS, Chew BP, McGuire MK, Fournier LR, Beerman KA. Soy isoflavones modulate immune function in healthy postmenopausal women. Am J Clin Nutr. 2006;83(5):1118-25.

54. Liu ZM, Ho SC, Chen YM, Ho YP. The effects of isoflavones combined with soy protein on lipid profiles, C-reactive protein and cardiovascular risk among postmenopausal Chinese women. Nutr Metab Cardiovasc Dis. 2012;22(9):712-9.

55. Li Z, Hong K, Saltsman P, DeShields S, Bellman M, Thames G, et al. Longterm efficacy of soy-based meal replacements vs an individualized diet plan in obese type II DM patients: relative effects on weight loss, metabolic parameters, and C-reactive protein. Eur J Clin Nutr. 2005;59(3):411-8.

56. Liu ZM, Ho SC, Chen YM, Ho S, To K, Tomlinson B, et al. Whole soy, but not purified daidzein, had a favorable effect on improvement of cardiovascular risks: a 6-month randomized, double-blind, and placebo-controlled trial in equol-producing postmenopausal women. Mol Nutr Food Res. 2014;58(4):709-17.

57. Hermansen K, Sondergaard M, Hoie L, Carstensen M, Brock B. Beneficial effects of a soy-based dietary supplement on lipid levels and cardiovascular risk markers in type 2 diabetic subjects. Diabetes Care. 2001;24(2):228-33.
58. Sanders TA, Dean TS, Grainger D, Miller GJ, Wiseman H. Moderate intakes of intact soy protein rich in isoflavones compared with ethanol-extracted soy protein increase HDL but do not influence transforming growth factor beta(1) concentrations and hemostatic risk factors for coronary heart disease in healthy subjects. Am J Clin Nutr. 2002;76(2):373-7.

59. Vega-Lopez S, Yeum KJ, Lecker JL, Ausman LM, Johnson EJ, Devaraj S, et al. Plasma antioxidant capacity in response to diets high in soy or animal protein with or without isoflavones. Am J Clin Nutr. 2005;81(1):43-9.

60. Harris W. Omega-6 and omega-3 fatty acids: partners in prevention. Curr Opin Clin Nutr Metab Care. 2010;13(2):125-9.

61. Fritz KL, Seppanen CM, Kurzer MS, Csallany AS. The invivo antioxidant activity of soy bean isoflavones in human subjects. Nutr Res. 2003;23(4):479-87.

62. Swain JH, Alekel DL, Dent SB, Peterson CT, Reddy MB. Iron indexes and total antioxidant status in response to soy protein intake in perimenopausal women. Am J Clin Nutr. 2002;76(1):165-71.

63. Cassidy A, Brown JE, Hawdon A, Faughnan MS, King $\sqcup$, Millward J, et al. Factors affecting the bioavailability of soy isoflavones in humans after ingestion of physiologically relevant levels from different soy foods. J Nutr. 2006;136(1):45-51.

64. Han RM, Tian YX, Liu Y, Chen CH, Ai XC, Zhang JP, et al. Comparison of flavonoids and isoflavonoids as antioxidants. J Agric Food Chem. 2009;57(9):3780-5.

65. Engelman HM, Alekel DL, Hanson LN, Kanthasamy AG, Reddy MB. Blood lipid and oxidative stress responses to soy protein with isoflavones and phytic acid in postmenopausal women. Am J Clin Nutr. 2005;81(3):590-6.

66. Azadbakht L, Nurbakhsh S. Effect of soy drink replacement in a weight reducing diet on anthropometric values and blood pressure among overweight and obese female youths. Asia Pac J Clin Nutr. 2011;20(3):383-9.

67. Deibert P, Konig D, Schmidt-Trucksaess A, Zaenker KS, Frey I, Landmann $U$, et al. Weight loss without losing muscle mass in pre-obese and obese subjects induced by a high-soy-protein diet. Int J Obes Relat Metab Disord. 2004;28(10):1349-52.

68. Liao FH, Shieh MJ, Yang SC, Lin SH, Chien YW. Effectiveness of a soy-based compared with a traditional low-calorie diet on weight loss and lipid levels in overweight adults. Nutrition. 2007;23(7-8):551-6.

69. Konig D, Deibert P, Frey I, Landmann U, Berg A. Effect of meal replacement on metabolic risk factors in overweight and obese subjects. Ann Nutr Metab. 2008;52(1):74-8.

\section{Publisher's Note}

Springer Nature remains neutral with regard to jurisdictional claims in published maps and institutional affiliations.

Ready to submit your research? Choose BMC and benefit from

- fast, convenient online submission

- thorough peer review by experienced researchers in your field

- rapid publication on acceptance

- support for research data, including large and complex data types

- gold Open Access which fosters wider collaboration and increased citations

- maximum visibility for your research: over 100M website views per year

At $\mathrm{BMC}$, research is always in progress.

Learn more biomedcentral.com/submissions 